\title{
Produktivitas Perikanan Tangkap Jaring Purse Seine
}

\section{The Productivity Of Purse Seine Net Fisheries Business}

\author{
Herna Octivia Damayanti \\ Badan Perencanaan Pembangunan Daerah Kabupaten Pati \\ Jl. Raya Pati-Kudus Km. 3,5, Margorejo, Pati. 59163. Jawa Tengah \\ *Email: octivia85@gmail.com
}

\begin{abstract}
Purse Seine net was one of the fishing gear with dominant catch results in Pati Regency. The catch results affected the business productivity of the purse seine net. The purpose of this research was to analyze the business productivity of the Purse Seine net fisheries in Pati Regency. The research was a descriptive study with a quantitative approach. The research was conducted in November 2018 until April 2019 with locations in Bajomulyo and Bendar Village, Juwana District, Pati Regency. The research sampling consisted of 56 samples. Data analysis with partial productivity calculation including productivity per trip, productivity per PK, productivity per crew and productivity per GT. The results showed that (1) the productivity of purse seine boat has exceeded the legalized regulations (1.30 tons/GT), (2) productivity per trip / per PK / per GT showed that the proxy of productivity (per trip, per PK, per GT) was not linearly proportional to the number of trip / PK engine / GT boat, (3) productivity per crew showed how much productivity per crew produced was not linearly proportional to the number of crews departed.
\end{abstract}

Keywords: marine fishery, purse seine net, productivity,

\begin{abstract}
ABSTRAK
Jaring Purse Seine merupakan salah satu alat tangkap dengan hasil tangkapan dominan di Kabupaten Pati. Hasil tangkapan berpengaruh terhadap produktivitas usaha jaring Purse Seine. Tujuan penelitian adalah untuk menganalisis produktivitas usaha perikanan jaring Purse Seine di Kabupaten Pati. Penelitian merupakan penelitian deskriptif dengan pendekatan kuantitatif. Waktu penelitian bulan November 2018 sampai dengan April 2019 dengan lokasi di Desa Bajomulyo dan Desa Bendar Kecamatan Juwana Kabupaten Pati. Sampel penelitian berjumlah 56 sampel. Analisis data dengan perhitungan produktivitas parsial yaitu produktivitas per trip, produktivitas per PK, produktivitas per ABK dan produktivitas per GT. Hasil penelitian menunjukkan bahwa (1) produktivitas kapal purse seine telah melebihi peraturan yang ditetapkan (1,30 ton/GT), (2) produktivitas per trip/per PK/per GT menunjukkan bahwa besar kecilnya produktivitas (per trip, per PK, per GT) tidak berbanding lurus dengan banyak sedikitnya jumlah trip/PK mesin/GT kapal, (3) produktivitas per ABK menunjukkan banyak sedikitnya produktivitas per ABK yang dihasilkan tidak berbanding lurus dengan banyak sedikitnya ABK yang diberangkatkan.
\end{abstract}

Kata kunci : perikanan tangkap, jaring purse seine, produktivitas

\section{PENDAHULUAN}

Indonesia memiliki 17.499 pulau dari Sabang hingga Merauke. Indonesia memiliki luas wilayah 7,81 juta $\mathrm{km}^{2}$ yang terdiri dari lautan mencapai $3,25 \mathrm{~km}^{2}$, daratan mencapai $2,01 \mathrm{~km}^{2}$, dan 2,55 juta $\mathrm{km}^{2}$ Zona Ekonomi Eksklusif (ZEE) (Roza, 2017).

Laut dipandang sebagai sumber daya yang terbuka bagi siapapun (open access) serta menjadi milik bersama (common property). Pandangan semacam ini menyebabkan siapapun bisa masuk dan mengambil sumber daya yang ada di dalamnya dengan peralatan apa saja serta dalam jumlah tidak terbatas. Pandangan tentang laut sebagai common property inilah yang dijadikan sebagai dasar bagi penjelasan krisis sumber daya laut (Cahyadi, 2012). Sumber daya ikan yang 
bersifat multispesies diperairan Indonesia dan bergantung pada lingkungannya menyebabkan adanya pola penyebaran ikan. Selain itu, karakteristik multispesies pada sumber daya ikan menyebabkan banyaknya penggunaan jenis alat tangkap untuk berbagai jenis ikan dalam kegiatan penangkapan ikan(Nelwan dkk., 2015).

Kabupaten Pati merupakan salah satu penghasil perikanan tangkap di Jawa Tengah. Tahun 2017, Kabupaten Pati menduduki peringkat pertama dengan kontribusi sebesar 21,083\% diikuti oleh Kabupaten Rembang dengan kontribusi 14,291\%; Kabupaten Batang 12,642\%; Kabupaten Pemalang dengan kontribusi $10,285 \%$ dan Kabupaten Cilacap dengan kontribusi 9,877\%. Jumlah produksi perikanan tangkap di Kabupaten Pati berupa ikan laut basah yang didominasi oleh jenis ikan layang, lemuru, kuniran, ekor kuning, mata besar dan kapasan(BPS Provinsi Jawa Tengah, 2019). Jenis ikan dominan (hasil tangkapan terbesar) merupakan ikan hasil tangkapan dengan alat tangkap jaring pukat cincin (purse seine) dan jaring cantrang.Alat tangkap cantrang dibatasi penggunaannya, sehingga jaring purse seine menjadi alat tangkap yang sangat berpotensi untuk terus dikembangkan penggunaannya.

Jenis ikan yang ditangkap tergolong dalam jenis ikan pelagis kecil dan merupakan salah satu jenis ikan yang dominan ditangkap oleh nelayan Kabupaten Pati. Silitonga dkk. (2016) menyebutkan bahwa dalam usaha penangkapan, alat tangkap yang digunakan oleh nelayan akan sangat memengaruhi hasil tangkapan, karena semakin efektif suatu alat tangkap maka semakin baik pula hasil tangkapan/produksi yang diperoleh. Produksi jenis ikan pelagis kecil diperoleh dari alat tangkap purse seine mempunyai prinsip interaksi antara alat tangkap dengan ikan yang menjadi tujuan penangkapan. Proses produksi ikan ditentukan oleh upaya penangkapan dan faktor lingkungan. Mirnawati dkk. (2019) menyebutkan bahwa upaya penangkapan merupakan tindakan efisiensi teknis yang dilakukan pelaku kegiatan penangkapan ikan, dimana upaya penangkapan adalah ukuran dari jumlah alat tangkap yang beroperasi untuk mendapatkan sejumlah hasil tangkapan atau lama alat tangkap beroperasi oleh berbagai unit penangkap ikan.

Tingkat produksi yang diperoleh secara langsung berpengaruh terhadap produktivitas usaha yang dijalankan. Produksi kelompok jenis ikan pelagis kecil diperoleh dari beberapa alat tangkap yang dioperasikan nelayan, namun alat tangkap yang efektif adalah purse seine (Nelwan dkk., 2015). Sebuah usaha (dalam hal ini usaha penangkapan ikan) selalu berkaitan dengan investasi, pembiayaan serta perolehan pendapatan (Damayanti, 2017). Penuturan dari nelayan jaring purse seine menyebutkan bahwa upaya penangkapan ikan dengan alat tangkap jaring purse seine di Kabupaten Pati sendiri dinilai belum efisien karena biaya operasional (pembiayaan) yang masih besar.

Biaya operasional yang masih besar menjadi pertimbangan dalam perhitungan jumlah dan lama trip yang akan dilakukan sehingga memengaruhi produktivitas suatu usaha. Tinggi atau rendahnya produktivitas suatu usaha akan memengaruhi besar kecilnya penerimaan dan pendapatan. Satrio (2014) menyebutkan bahwa peningkatan produktivitas merupakan prioritas utama pertumbuhan ekonomi yang harus segera dilaksanakan dalam menghadapi tantangan perkembangan ekonomi karena tingkat produktivitas dapat menggambarkan tingkat kesejahteraan masyarakat.

Selain faktor biaya operasional yang besar, produktivitas, dan ketersediaan ikan bervariasi dari tahun ke tahun seiring dengan perubahan kondisi lingkungan laut. Kondisi tersebut tidak dapat dihindarkan sehingga perikanan tangkap sulit diprediksi atau bersifat ketidakpastian (Nelwan dkk., 2015). Berdasarkan latar belakang tersebut, tujuan penelitian adalah untuk menganalisis produktivitas usaha perikanan jaring purse seine di Kabupaten Pati. 


\section{TINJAUAN PUSTAKA}

\section{Jaring Purse Seine}

Pukat cincin atau biasa disebut dengan "purse seine" adalah alat penangkap ikan yang dipergunakan untuk menangkap ikan pelagis yang bergerombol seperti: kembung, lemuru, layang, tongkol, cakalang, dan lain sebagainya. purse seine adalah alat penangkap ikan yang bagian utamanya adalah jarring yang dipergunakan untuk menangkap ikan pelagis besar atau ikan pelagis kecil sesuai dengan ukuran dan jumlah yang banyak (Pusat Pendidikan Kelautan dan Perikanan Ambon, 2012).

Purse seine berbentuk persegi panjang dengan pelampung (floats) di bagian atas dan pemberat (sinkers) serta cincin besi (rings) di bagian bawah. Saat dioperasikan, kapal yang membawa jaring purse seine melingkari sekawanan ikan yang telah dikumpulkan dengan pemikat rumpon dan lampu berkekuatan tinggi. Setelah lingkaran terbentuk sempurna, maka tali kolor (purse line) yang terdapat di bagian bawah selanjutnya akan ditarik melewati cincin-cincin besi yang bergelantungan di bagian bawah jaring sehingga jaring mengerucut dan berbentuk seperti mangkok dengan segerombolan ikan yang terkurung di dalamnya (Pusat Pendidikan Kelautan dan Perikanan Ambon, 2012).

Pukat cincin (Purse seine) merupakan salah satu tipe alat penangkapan ikan yang menggunakan cahaya dalam pengoperasiannya. Cahaya dalam hal ini berfungsi untuk menarik perhatian ikan. Penggunaan cahaya sebagai daya tarik (lure) ikan merupakan salah satu teknologi penangkapan yang dianggap sukses dan mengalami perkembangan yang pesat (Arimoto dalam Mahiswara dkk., 2009). Fungsi utama cahaya adalah sebagai alat bantu untuk mengumpulkan ikan. Ikan yang tersebar di daerah penangkapan, dengan menggunakan cahaya ditarik sehingga berkumpul di sekitar unit penangkapan. Pengoperasian alat tangkap (Purse seine) dilakukan apabila ikan yang telah berkumpul di area tangkap (catching area) berdasarkan pada perhitungan layak untuk ditangkap. Sasaran spesies pengoperasian Purse seine adalah sumber daya ikan pelagis (kecil dan besar) yang memiliki sifat tertarik dengan rangsang cahaya (memilki sifat fototaksis positif) (Mahiswara dkk., 2009).

Hasil tangkapan purse seine antara lain layang (Decapterus ruselli), cakalang (Katsuwonus pelamis), tongkol (Auxis thazard), tembang (Sardinella brachysoma), kembung (Rastrelliger $s p$ ), teri (Stolephorus spp), cendro (Tylosorus crocodulus), tenggiri (Scomberomorus commerson), dan peperek (Leiognatus spp), kuwe (Caranx sexfasciatus) (Najamuddin dkk., 2017).

Secara umum, material penyusun pukat cincin (purse seine) terdiri dari (Pusat Pendidikan Kelautan dan Perikanan Ambon, 2012) :

1. Kantong (bund)

Kantong adalah bagian jaring yang pada waktu penarikan tali kolor dengan serentaknya membentuk suatu kantong, yang nantinya berfungsi sebagai tempat untuk mengurung/ mengumpulkan ikan. Sebagai penadah, maka kantong memiliki ukuran mata jaring yang lebih kecil dibandingkan mata jaring yang terletak pada badan dan sayap sehingga ikanikan yang telah terkumpul pada bagian kantong tidak fapat meloloskan diri.

2. Badan (body)

Badan jaring terletak pada bagian kiri dan kanan dari pada kantong yang berfungsi sebagai pengiring ikan kebagian jaring. Dengan demikian maka ikan-ikan akan dengan mudah terkumpul pada bagian kantong.

3. Sayap (wing)

Sayap terletak pada bagian kiri dan kanan badan jaring. Sayap jaring berfungsi sebagai alat untuk mengiring ikan kedalam areal tangkap dari alat ini.

4. Pelampung (float)

Sesuai dengan namanya sudah barang tentu pelampung ini berfungsi sebagai alat untuk mengapungkan sesuatu alat atau bagianbagian alat tertentu dari suatu jenis alat sesuai dengan tujuannya. 


\section{Tali Temali}

Beberapa tali temali pada alat tangkap pukat cincin sesuai dengan fungsinya adalah sebagai berikut:

- Tali Pelampung (float Line) sebagai tempat pelampung

- Tali Ris Atas sebagai tempat untuk mengantungkan daging jaring, selain itu pula untuk mempermudah penarikan alat

- Tali Pemberat untuk menempatkan/ memasang pemberat

- Tali cincin untuk mengantungkan cincin

- Tali kolor untuk mengantungkan cincin

- Bridle line, tali tempat untuk mengantungkan tepi jaring (selvage) sebelah samping yang berfungsi untuk menarik tali pemberat serta tali kolor kepermukaan.

- Tali sama-sama, tali yang dipasangkan pada bagian ujung sebelah kiri dan kanan jaring yang dapat berfungsi untuk mempertemukan kedua ujung jaring serta dapat berfungsi sebagai alat bantu (perahu semang) sebagai tanda untuk dapat mengetahui ujung jaring pada waktu penebaran (setting).

- Tali bantu, tali yang dipasang untuk memisahkan sero dengan tali jangkar. Tali ini juga khusus dipakai untuk membantu dalam penangkapan dengan cara melingkar sero.

6. Cincin

Cincin merupakan tempat lewatnya tali kolor, cincin yang terletak tepat ditengah jaring yang telah diberi tanda khusus untuk dapat memudahkan pada saat penyusunan alat kembali.

\section{Pemberat (singker)}

Pemberat pada jaring berfungsi untuk dapat menarik jaring kebawah secara fertikal agar jaring dapat terentang dengan sempurna. Material pembentuk pemberat yang digunakan adalah timah hitam yang diletakan pada bagian sayap dari pada jaring.

H. Galah

Terbuat dari kayu atau bambu yang pada bagian ujungnya diberi cabang yang digunakan untuk mengeluarkan jaring dari sero (rakit rumpon) pada saat melakukan operasi penangkapan, caranya yaitu pelampung pada sisi kiri dan kanan dari sero (rakit rumpon) ditekan ke dalam air pada saat permukaan jaring akan meliwati sero, sedangkan yang satu lagi berfungsi untuk mengangkat tali bantu keatas perahu jaring pada saat kegiatan melingkari sero (rakit rumpon).

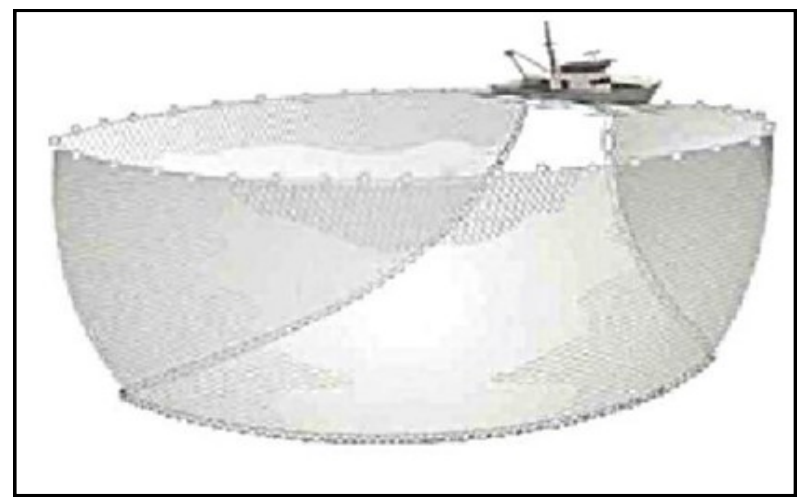

Gambar 1.

Jaring Lingkar Bertali Kerut (Purse Seine)

(Kementerian Kelautan dan Perikanan Republik Indonesia, 2017)

\section{Ikan Pelagis Kecil}

Sumber daya ikan pelagis adalah jenisjenis ikan yang sebagian besar siklus hidupnya berada di permukaan atau dekat permukaan perairan dengan karakteristik membentuk gerombolan yang cukup besar dan beruaya (migrasi) yang cukup jauh dengan gerak/ aktivitas yang cepat.

Kelimpahan ikan pelagis sangat peka terhadap perubahan lingkungan terutama penyebaran salinitas secara spasial yang dibangkitkan oleh angin muson. Pada tahun basah, saat curah hujan di atas normal (musim barat) penetrasi ikan oseanik ke Laut Jawa berkurang akibat pengurangan massa air oseanik di bagian timur Laut Jawa. Terdapat korelasi positif antara hasil tangkapan dengan salinitas permukaan, tetapi korelasi ini menunjukan negatif dengan curah hujan. Secara spasial, ikan pelagis tersebar ke arah timur dengan konsentrasi kelimpahan berada di Laut Jawa bagian timur, variabilitas beberapa jenis ikan berasosiasi dengan perubahan salinitas (Balai Riset Perikanan Laut dalam Chodriyah \& Hariati, 2010). 
Kasim dkk. (2011) menyebutkan bahwa produksi perikanan pelagis di Indonesia sebagian besar didaratkan di Pantai Utara Jawa dan telah dieksploitasi secara intensif pada awal tahun 1980 an sejak diperkenalkannya mekanisasi alat-alat penangkapan ikan dan penggunaan alat tangkap purse seine.

Jenis-jenis ikan pelagis yang dominan tertangkap nelayan di Laut Jawa terdiri dari pelagis besar dan pelagis kecil. Jenis ikan pelagis besar yang dominan antara lain tongkol komo (Euthynnus affinis), tongkol abu-abu (Thunnus tonggol), serta tenggiri (Scomberomorus sp) (Ma'mun dkk., 2019). Sumber daya ikan pelagis kecil yang paling umum antara lain adalah layang, kembung, selar, tembang, lemuru, teri, dan ikan terbang (Balai Penelitian Perikanan Laut, Pusat Penelitian Pengelolaan Perikanan dan Konservasi Sumber Daya Ikan, 2014). Terdapat 16 jenis sumber daya ikan pelagis kecil yang tertangkap di Laut Jawa di mana enam jenis diantaranya memberikan kontribusi lebih dari 90\% total hasil tangkapan, yaitu layang (Decapterus russellli), layang deles (Decapterus macrosoma), selar (Selaroides leptolepis), bentong (Selar crumenophthalmus), banyar/ kembung lelaki (Rastrelliger kanagurta), siro/ lemuru (Amblygaster sirm) dan tembang/juwi (Sardinella fimbriata) (Kasim dkk., 2014).

Ikan pelagis kecil merupakan ikan yang selalu melakukan migrasi untuk mencari makan maupun untuk melakukan pemijahan. Ikan pelagis kecil dalam melakukan migrasi mencari suhu yang dapat ditolerir dengan kehidupannya. Zona potensi penangkapan ikan pelagis kecil pada musim barat dan musim timur memiliki perbedaan disebabkan sebaran akumulasi konsentrasi klorofil-a (0,50-2,50 $\mathrm{mg} / \mathrm{m}^{3}$ ) dan sebaran optimum suhu permukaan laut (26-29 $\left.{ }^{\circ} \mathrm{C}\right)$ untuk persyaratan hidup ikan pelagis kecil (Kurniawati dkk., 2015). Daerah potensial penangkapan ikan pelagis juga dapat diidentifikasi dan dilokalisasi pada daerah yang merupakan daerah upwelling (Safruddin dkk., 2014).

\section{Produktivitas}

Produktivitas merupakan konsep universal yang berlaku bagi semua sistem ekonomi dan sistem sosial. Produktivitas adalah mesin utama pertumbuhan ekonomi global. Meningkatkan produktivitas merupakan tantangan mendasar bagi negara-negara maju (McGowan et al., 2015). Produktivitas secara umum diartikan sebagai hubungan antara keluaran (barang atau jasa) dengan masukan (faktor produksi) (Hermawan \& Rustiana, 2019).

Yadav \& Marwah (2015) mendeskripsikan produktivitas sebagai rasio antara output dan input yang digunakan dalam proses produksi. Gordon et al. (2015) menyebutkan bahwa produktivitas tumbuh ketika output tumbuh lebih cepat daripada input, yang membuat input yang ada berproduksi lebih efisien. Produktivitas tidak mencerminkan seberapa besar menghargai output tetapi hanya mengukur seberapa efisien kita menggunakan sumber daya untuk memproduksinya. Lebih lanjut Gordon et al. (2015) menyebutkan bahwa pertumbuhan produktivitas berasal dari pertumbuhan ekonomi produktif yang potensial, yaitu tingkat output maksimum yang dapat dihasilkan mengingat ketersediaan tenaga kerja, modal, sumber daya, dan teknologi.

\section{Produktivitas Perikanan Tangkap}

Produktivitas perikanan tangkap adalah produktivitas dari kapal/perahu yang digunakan dalam perikanan tangkap. Produktivitas kapal penangkap ikan dapat diartikan sebagai tingkat kemampuan kapal penangkap ikan dalam memperoleh hasil tangkapan ikan per tahun. Produktivitas kapal penangkap ikan per tahun dapat dihitung dari jumlah hasil tangkapan ikan per kapal dalam satu tahun dibagi besarnya jumlah kapal yang bersangkutan. Besar kecilnya produktivitas penangkapan tersebut akan menentukan tingkat kelayakan tersebut akan menentukan tingkat kelayakan usaha (Saputra dkk., 2011). 
Produktivitas kapal penangkap ikan per tahun dihitung berdasarkan pembagian antara jumlah hasil tangkapan ikan per kapal dalam 1 (satu) tahun dengan besarnya GT kapal tersebut (Lesmana dkk., 2017). Berdasarkan Rajagukguk (2018), produktivitas penangkapan ikan dipengaruhi beberapa faktor. Jika faktorfaktor tersebut maksimal, maka produktivitas penangkapan ikan akan tinggi begitu pula sebaliknya. Sementara itu, menurut KepMen KKP Nomor 86 Tahun 2016, produktivitas kapal penangkap ikan merupakan tingkat kemampuan memperoleh hasil tangkapan ikan yang ditetapkan dengan mempertimbangkan: (a) ukuran tonnage kapal, (b) bahan kapal yang digunakan kayu atau besi/fiber, (c) kekuatan mesin kapal, (d) jenis alat penangkapan ikan yang digunakan, (e) jumlah trip operasi penangkapan per tahun, (f) kemampuan tangkap rata-rata per trip, dan (g) wilayah penangkapan ikan.

Produktivitas penangkapan yang diukur berdasarkan perbandingan antara produksi dengan upaya penangkapan menjadi tolok ukur kemampuan tangkap suatu alat tangkap. Setiap jenis alat tangkap mempunyai prinsip penangkapan yang berbeda, sehingga kemampuan tangkap dalam produksi juga berbeda (Olii \& Iwan, 2018).

\section{METODE PENELITIAN}

Penelitian merupakan penelitian deskriptif menggunakan pendekatan kuantitatif. Penelitian kuantitatif menekankan analisisnya pada data-data numerikal (angka) yang diolah dengan metode statistika (Azwar, 2003). Penelitian dilakukan pada bulan November 2018 hingga April 2019 dengan lokasi Desa Bajomulyo dan Desa Bendar Kecamatan Juwana Kabupaten Pati. Pemilihan lokasi berdasarkan data dari Pelabuhan Perikanan Pantai (PPP) Bajomulyo mencatat bahwa mayoritas nelayan pemilik jaring purse seine berada di Desa Bajomulyo dan Desa Bendar Kecamatan Juwana Kabupaten Pati.
Responden penelitian (sampel) adalah nelayan pemilik kapal jaring purse seine berjumlah 56 nelayan. Adapun 27 responden berasal dari Desa Bajomulyo dan 29 responden dari Desa Bendar. Penelitian menggunakan data primer dan data sekunder. Data primer diperoleh melalui pengisian kuesioner, sedangkan data sekunder berupa dokumen yang berasal dari instansi terkait. Teknik pengambilan sampel penelitian dilakukan secara random sederhana dengan tahapan sebagai berikut:

- Penentuan populasi penelitian

Berdasarkan data PPP Bajomulyo (2017) populasi penelitian yaitu 56 purse seine. Populasi ini diperoleh berdasarkan kriteria-kriteria tertentu:

Tabel 1.

Kriteria Populasi Penelitian

\begin{tabular}{cl}
\hline No. & \multicolumn{2}{c}{ Kriteria } \\
\hline 1. & Ukuran kapal 70-90 GT \\
2. & Lokasi di Desa terdekat dengan TPI \\
& Bajomulyo (Desa Bendar dan Bajomulyo) \\
\hline
\end{tabular}

Sumber : Analisis Data Primer (2019)

- Penentuan responden penelitian

Menentukan responden penelitian yaitu semua populasi digunakan sebagai responden penelitian. Persebaran responden penelitian disajikan pada Tabel 2.

Analisis data dilakukan dengan menghi-

Tabel 2.

Persebaran Responden Penelitian

\begin{tabular}{clc}
\hline No & Lokasi & Sampel \\
\hline 1 & Desa Bajomulyo & 27 \\
2 & Desa Bendar & 29 \\
& Jumlah & 56 \\
\hline
\end{tabular}

Sumber : Analisis Data Primer (2019)

tung produktivitas parsial usaha perikanan jaring purse seine. Produktivitas/kelimpahan sumber daya ikan dari suatu perairan dihitung dengan membagi jumlah ikan (catch) yang tertangkap oleh alat tangkap eksplorasi dengan jumlah trip penangkapan (effort) (Wiyono, 2012). Hal tersebut sesuai Keputusan Menteri Kelautan dan Perikanan Nomor 38 Tahun 2003 yang menyebutkan bahwa produktivitas kapal penangkap ikan adalah tingkat kemampuan ka- 
penangkap ikan adalah tingkat kemampuan kapal penangkap ikan untuk memperoleh hasil tangkapan ikan per tahun (KKP, 2003). Produksi per trip (catch per unit effort) dihitung berdasarkan jumlah produksi (volume hasil tangkapan) dan jumlah trip. Secara matematis dirumuskan sebagai berikut:

Produktivitas per trip $=\frac{\sum \text { produksi }}{\sum \text { trip penangkapan }}($ ton/trip $)$

Menurut Choliq dkk. (1994), pengukuran produktivitas dari alat tangkap meliputi produktivitas per $\mathrm{PK}$, produktivitas per $\mathrm{ABK}$, dan produktivitas per GT. Adapun rumusnya adalah sebagai berikut :

Produktivitas per unit per trip $=\frac{\sum \text { produksi }}{P K}(\operatorname{ton} / \mathrm{PK})$

Produktivitas per $A B K$ per trip $=\frac{\sum \text { produksi }}{A B K}($ ton/orang $)$

Berdasarkan Peraturan Menteri Kelautan dan Perikanan Nomor 60 Tahun 2014, produktivitas kapal penangkap ikan (KKP, 2014) adalah sebagai berikut:

Produktivitas per $G T=\frac{\sum \text { produksi }}{G T}($ ton $/ G T)$

\section{HASIL DAN PEMBAHASAN}

\section{Profil Responden Nelayan Jaring Purse Seine}

Pengisian kuesioner dilakukan oleh 56 nelayan sebagai responden penelitian. Dari jumlah tersebut, sebanyak 27 nelayan berasal dari Desa Bajomulyo dan 29 nelayan dari Desa Bendar. Umur minimum responden adalah 31 tahun, sedangkan umur maksimum responden 69 tahun, rata-rata umur responden adalah 47,75 tahun dengan standar deviasi 9,22 tahun. Mayoritas pendidikan responden adalah SMU. Pengalaman nelayan paling rendah adalah 10 tahun, sementara pengalaman nelayan paling tinggi adalah 46 tahun. Rata-rata pengalaman nelayan adalah 16,93 tahun dengan standar deviasi 8,00 tahun. Profil res-ponden nelayan jaring purse seine disajikan pada Tabel 3.

\section{Produksi Jaring Purse Seine Kabupaten Pati}

Hasil tangkapan dengan alat tangkap purse seine menunjukkan fluktuasi selama 10 tahun terakhir, bahkan jumlah produksinya belum mampu menyamai jumlah produksi tahun

Tabel 3.

Profil Responden Nelayan Jaring Purse Seine

\begin{tabular}{|c|c|c|c|}
\hline No & Keterangan & Desa Bajomulyo & Desa Bendar \\
\hline 1 & Jumlah & 27 & 29 \\
\hline \multirow[t]{8}{*}{2} & Umur & & \\
\hline & & Minimum = 31 & Mean $=47,75$ \\
\hline & & Maksimum $=69$ & Std. Deviation $=9,22$ \\
\hline & Rincian Jumla & & \\
\hline & $30-40$ tahun & 4 & 9 \\
\hline & 41-50 tahun & 12 & 16 \\
\hline & 51-60 tahun & 6 & 4 \\
\hline & $>60$ tahun & 5 & 0 \\
\hline \multirow[t]{5}{*}{3} & Pendidikan & & \\
\hline & SD & 3 & 3 \\
\hline & SMP & 2 & 0 \\
\hline & SMU & 21 & 20 \\
\hline & Sarjana & 1 & 6 \\
\hline \multirow[t]{9}{*}{4} & Pengalaman $r$ & ayan & \\
\hline & & Minimum $=10$ & Mean $=16,93$ \\
\hline & & Maksimum = 46 & Std. Deviation $=8,00$ \\
\hline & Rincian Jumla & & \\
\hline & 0-10 tahun & 12 & 10 \\
\hline & 11-20 tahun & 10 & 15 \\
\hline & 21-30 tahun & 5 & 3 \\
\hline & $31-40$ tahun & 0 & 0 \\
\hline & $>40$ tahun & 0 & 1 \\
\hline
\end{tabular}


Tabel 4.

Produksi Perikanan Jaring Purse Seine di Kabupaten Pati

\begin{tabular}{|c|c|c|c|c|c|c|c|c|c|c|}
\hline \multirow[b]{2}{*}{ Tahun } & \multirow{2}{*}{$\begin{array}{c}\text { Produksi } \\
\text { Perikanan } \\
\text { Tangkap } \\
\text { (Ton) }\end{array}$} & \multicolumn{8}{|c|}{ Produksi Purse Seine (Ton) } & \multirow{2}{*}{$\begin{array}{c}\text { Share } \\
\text { Produksi } \\
\text { Purse } \\
\text { Seine } \\
\text { Terhadap } \\
\text { Total (\%) }\end{array}$} \\
\hline & & Layang & Kembung & Selar & Tembang & Tongkol & Lemuru & Total & $\begin{array}{c}\text { Ptumb } \\
(\%)\end{array}$ & \\
\hline 2009 & $39.308,31$ & $20.088,07$ & 518,04 & 770,84 & 736,54 & 730,39 & $3.379,75$ & $26.223,63$ & 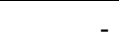 & 66,71 \\
\hline 2010 & $38.718,05$ & $17.209,17$ & 217,22 & 436,04 & 261,36 & 378,47 & $3.341,98$ & $21.844,24$ & $-16,70$ & 56,42 \\
\hline 2011 & $44.043,32$ & $23.429,12$ & 500,29 & 506,54 & 176,20 & 653,83 & $2.278,81$ & $27.544,79$ & 26,10 & 62,54 \\
\hline 2012 & $47.576,65$ & $26.540,02$ & 362,85 & 226,67 & 114,60 & 417,85 & $3.149,25$ & $30.811,24$ & 11,86 & 64,76 \\
\hline 2013 & $32.170,80$ & $11.239,21$ & 184,45 & 150,62 & 341,72 & 414,73 & $3.252,91$ & $15.583,64$ & $-49,42$ & 48,44 \\
\hline 2014 & $32.286,07$ & $5.599,44$ & 24,27 & 80,26 & 49,52 & 103,47 & 228,31 & $6.085,27$ & $-60,95$ & 18,85 \\
\hline 2015 & $52.792,95$ & $14.633,99$ & 47,63 & 251,97 & 84,39 & 118,57 & $2.548,10$ & $17.684,64$ & 190,61 & 33,50 \\
\hline 2016 & $54.749,10$ & $15.160,22$ & 22,80 & 357,8 & 355,45 & 67,36 & $4.216,37$ & $20.179,99$ & 14,11 & 36,86 \\
\hline 2017 & $26.734,29$ & $17.455,01$ & 72,21 & 12,87 & 814,07 & 35,90 & $3.505,93$ & $21.896,00$ & 8,50 & 81,90 \\
\hline 2018 & $23.517,49$ & $12.048,10$ & 45,20 & 19,80 & 520,60 & 5,80 & $4.175,40$ & $16.814,90$ & $-23,21$ & 71,50 \\
\hline
\end{tabular}

Sumber: BPS Kabupaten Pati Diolah (2019)

2009-2012. Tahun 2018 jumlah produksi justru mengalami penurunan sebesar $23,21 \%$, sebagaimana ditampilkan pada Tabel 4 .

Share (persentase) produksi jaring purse seine terhadap total produksi perikanan tangkap di Kabupaten Pati mengalami fluktuasi tiap tahunnya (mulai dari tahun 2009-2018). Share produksi terbesar terjadi pada tahun 2017 dengan persentase sebesar 81,90\% dan share produksi terkecil terjadi pada tahun 2014 yaitu $18,85 \%$.

\section{Profil Alat Tangkap Jaring Purse Seine}

Berdasarkan hasil wawancara dengan nelayan pemilik jaring purse seine diperoleh gambaran tentang alat tangkap jaring purse seine yang digunakan untuk menangkap ikan (Tabel 5). Kelebihan jaring purse seine menurut para responden adalah ramah lingkungan dan hasil tangkapan banyak. Kelemahan jaring purse seine yaitu modal pembuatan jaring besar, proses pengurusan perizinan lama, lokasi penangkapan jauh, dan biayanya mahal.

Tabel 5.

Profil Alat Tangkap Jaring Purse Seine di Kabupaten Pati

\begin{tabular}{|c|c|}
\hline Uraian & Jaring Purse Seine \\
\hline Nama Indonesia & : Jaring lingkar bertali kerut \\
\hline Nama Lain & : Pukat cincin \\
\hline Klasifikasi & : $\quad$ Surrounding nets \\
\hline (PerMEn KP No. PER & \\
\hline $02 / \mathrm{MEN} / 2011)$ & \\
\hline Ukuran (luas) & $100-350 \mathrm{~m}^{2}$ \\
\hline Mekanisme & $\begin{array}{l}\text { Mencari kawanan ikan, kemudian menyalakan lampu untuk menarik perhatian } \\
\text { ikan. Setelah ikan berkumpul, alat tangkap diturunkan. Lampu kemudian } \\
\text { difokuskan pada satu titik, disertai dengan proses surrounding alat tangkap. } \\
\text { Langkah selanjutnya adalah proses pursing yaitu menarik tali kerut pada bagian } \\
\text { bawah jaring agar membentuk kantong dan menjebak ikan didalamnya. Tahap } \\
\text { akhir adalah hauling yaitu menaikkan jaring ke kapal }\end{array}$ \\
\hline Hasil Tangkapan & : Layang, kembung, selar, tembang, tongkol, lemuru \\
\hline \multirow[t]{3}{*}{ Area Penangkapan } & : $\quad$ Laut Jawa (WPP RI 712) \\
\hline & Selat Makassar, Teluk Bone, Laut Flores dan Laut Bali (WPP RI 713) \\
\hline & Laut Aru, Laut Arafuru dan Laut Timor Bagian Timur (WPP RI 718) \\
\hline Lampu & Halogen ( $8-48$ buah) \\
\hline Ukuran GT & : $\quad 70,71,72,73,74,75,76,77,79,81,82,83,84,85,86,87,88,89,90$ \\
\hline Jumlah & : 56 unit alat tangkap jaring Purse Seine \\
\hline Sebaran & : Desa Bajomulyo dan Desa Bendar \\
\hline
\end{tabular}

Sumber: Pengolahan Data (2019) 
Tabel 6.

Profil Usaha Perikanan Jaring Purse Seine

\begin{tabular}{lcrrrr}
\hline \multicolumn{1}{c}{ Variabel } & satuan & Minimum & Maksimum & \multicolumn{1}{l}{ Mean } & \multicolumn{1}{c}{ Std.Deviation } \\
\hline Produksi & & & & & \\
- Puncak & ton & 10 & 270 & 60,80 & 42,94 \\
- Biasa & ton & 16 & 150 & 56,00 & 22,46 \\
- Paceklik & ton & 11 & 100 & 43,68 & 16,71 \\
Lama Trip & & & & & \\
- Puncak & hari & 30 & 120 & 57,14 & 19,04 \\
- Biasa & hari & 45 & 120 & 86,52 & 22,82 \\
- Paceklik & hari & 60 & 150 & 102,50 & 21,68 \\
Solar & & & & & \\
- Puncak & liter & 8.000 & 48.000 & 20.100 & $7.549,00$ \\
- Biasa & liter & 16.000 & 48.000 & 30.200 & $8.769,24$ \\
- Paceklik & liter & 19.200 & 64.000 & 36.100 & $10.245,69$ \\
Oli & & & & & \\
- Puncak & liter & 24 & 640 & 101,14 & 91,55 \\
- Biasa & liter & 48 & 640 & 145,71 & 99,75 \\
- Paceklik & liter & 48 & 640 & 172,00 & 104,17 \\
Luas Jaring & m & 100 & 350 & 290,00 & 73,36 \\
Mesin & PK & 200 & 400 & 300,00 & 48,62 \\
Konsumsi & & & & & \\
- Puncak & Rp & 8.000 .000 & 300.000 .000 & 71.400 .000 & 59.930 .000 \\
- Biasa & $\mathrm{Rp}$ & 10.000 .000 & 300.000 .000 & 110.000 .000 & 87.560 .000 \\
- Paceklik & $\mathrm{Rp}$ & 10.000 .000 & 300.000 .000 & 127.000 .000 & 89.470 .000 \\
ABK & org & 25 & 50 & 33,82 & 6,09 \\
\hline
\end{tabular}

Sumber: Analisis Data Primer (2019)

\section{Profil Usaha Perikanan Jaring Purse Seine}

Rata-rata produksi untuk semua ukuran GT kapal jaring purse seine pada musim puncak 60,80 ton; musim biasa 56,00 ton; musim paceklik 43,68 ton. Rata-rata lama trip pada musim puncak adalah 57,14 hari; musim biasa 86,52 hari dan musim paceklik 102,50 hari. Rata-rata penggunaan BBM solar pada musim puncak 20.100 liter; musim biasa 30.200 liter dan musim paceklik 36.100 liter. Rata-rata penggunaan oli pada musim puncak adalah 101,14 liter; musim biasa 145,71 liter dan musim paceklik 172,00 liter.

Rata-rata luas jaring purse seine yang digunakan adalah 290,00 $\mathrm{m}^{2}$. Rata-rata kapasitas mesin yang dipakai adalah 300,00 PK. Ratarata konsumsi pada musim puncak adalah
Rp71.400.000,00; musim biasa adalah Rp110.000.000,00; dan musim paceklik adalah Rp127.000.000,00. Rata-rata jumlah ABK untuk satu kapal jaring purse seine adalah 33,82 orang.

\section{Produktivitas Usaha Perikanan Jaring Purse Seine}

Produktivitas unit penangkapan ikan purse seine adalah hasil tangkapan yang dapat dihasilkan oleh setiap armada penangkapan untuk menangkap ikan (Rajagukguk, 2018). Produktivitas usaha perikanan jaring purse seine terdiri dari produktivitas per trip, per $\mathrm{PK}$, per ABK dan per GT. Produktivitas per trip ratarata usaha perikanan jaring purse seine yaitu 54,450 ton/trip. Produktivitas per PK rata-rata 
yaitu 0,960 ton/PK. Produktivitas per ABK ratarata yaitu 8,096 ton/org. Produktivitas per GT rata-rata yaitu $3,457 \mathrm{~kg} / \mathrm{GT}$. Produktivitas unit penangkapan ikan purse seine adalah hasil tangkapan yang dapat dihasilkan oleh setiap armada penangkapan untuk menangkap ikan (Rajagukguk, 2018). Produktivitas usaha perikanan jaring purse seine terdiri dari produktivitas per trip, per $\mathrm{PK}$, per ABK dan per GT. Produktivitas per trip rata-rata usaha perikanan jaring purse seine yaitu 54,450 ton/trip. Produktivitas per PK rata-rata yaitu 0,960 ton/ PK. Produktivitas per ABK rata-rata yaitu 8,096 ton/org. Produktivitas per GT rata-rata yaitu $3,457 \mathrm{~kg} / \mathrm{GT}$.

\section{a) Produktivitas Per Trip}

Produktivitas unit penangkapan purse seine per trip merupakan kemampuan unit penangkapan purse seine untuk menghasilkan ikan setiap trip, artinya jumlah hasil tangkapan ikan yang dihasilkan oleh setiap kali kapal purse seine melakukan penurunan jaring (Rajagukguk, 2018). Produktivitas per trip usaha perikanan jaring purse seine dapat dibagi menjadi tiga yaitu untuk jumlah trip 4 kali dalam satu tahun, jumlah trip 5 kali dalam setahun dan jumlah trip 6 kali dalam satu tahun. Hasil perhitungan produktivitas per trip disajikan pada Tabel 8.

Tabel 8 menunjukkan bahwa produktivitas per trip untuk kapal jaring purse seine dengan jumlah trip setahun 4 kali adalah 66,804 ton/trip; produktivitas per trip dengan jumlah trip setahun 5 kali adalah 50,929 ton/ trip; dan produktivitas per trip dengan jumlah trip setahun 6 kali adalah 45,619 ton/trip. Berdasarkan data tersebut dapat dinyatakan bahwa produktivitas lebih besar dihasilkan oleh kapal purse seine dengan jumlah trip yang lebih sedikit. Hal yang menjadi penyebabnya adalah untuk jumlah trip 4 kali dalam setahun, lama tripnya berkisar antara 90-120 hari sehingga upaya penangkapan yang dilakukan dapat lebih optimal. Sementara itu, usaha perikanan jaring purse seine dengan jumlah trip 6 memiliki lama trip berkisar 30-60 hari, sedangkan usaha perikanan jaring purse seine dengan jumlah trip 5 lama tripnya berada diantara 61-89 hari. Pada lama trip 30-60 hari, upaya penangkapan yang dilakukan tidak optimal dan tidak efisien karena waktu banyak terbuang untuk perjalanan berangkat dan pulang serta untuk istirahat.

Selain itu, jumlah trip yang terlalu banyak membutuhkan waktu adaptasi kembali dengan lingkungan area penangkapan yang berakibat semakin tidak efisiennya upaya penangkapan yang dilakukan. Jumlah trip yang dilakukan harus disesuaikan dengan jumlah stok ikan di lokasi penangkapan sehingga upaya penangkapan yang dilakukan lebih efisien dan mendapatkan hasil yang optimal. Alhuda dkk. (2016) menyebutkan salah satu hal yang memengaruhi produktivitas adalah jumlah upaya penangkapan (trip) yang melebihi jumlah stok sumber daya (overfishing). Hal ini juga menunjukkan bahwa besar kecilnya produktivitas per trip yang dihasilkan tidak berbanding lurus dengan banyak sedikitnya jumlah trip yang dilakukan.

Tabel 7.

Produktivitas Usaha Perikanan Jaring Purse Seine

\begin{tabular}{llllll}
\hline Variabel & satuan & Minimum & Maksimum & Mean & Std.Deviation \\
\hline Prod/trip & ton/trip & 45,619 & 66,804 & 54,450 & 11,023 \\
Prod/PK & ton/PK & 0,550 & 1,266 & 0,960 & 0,287 \\
Prod/ABK & ton/org & 2,160 & 16,279 & 8,096 & 3,900 \\
Prod/GT & ton/GT & 2,560 & 7,778 & 3,457 & 1,126 \\
\hline
\end{tabular}

Sumber: Analisis Data Primer (2019) 
Tabel 8.

Produktivitas Usaha Perikanan Jaring Purse Seine

\begin{tabular}{cc}
\hline Jumlah Trip Per Tahun & Produktivitas Per Trip (ton/trip) \\
\hline 6 & 45,619 \\
5 & 50,929 \\
4 & 66,804 \\
\hline
\end{tabular}

Sumber: Analisis Data Primer (2019)

\section{a) Produktivitas Per Trip}

Produktivitas unit penangkapan purse seine per trip merupakan kemampuan unit penangkapan purse seine untuk menghasilkan ikan setiap trip, artinya jumlah hasil tangkapan ikan yang dihasilkan oleh setiap kali kapal purse seine melakukan penurunan jaring (Rajagukguk, 2018). Produktivitas per trip usaha perikanan jaring purse seine dapat dibagi menjadi tiga yaitu untuk jumlah trip 4 kali dalam satu tahun, jumlah trip 5 kali dalam setahun dan jumlah trip 6 kali dalam satu tahun. Hasil perhitungan produktivitas per trip disajikan pada Tabel 8.

Tabel 8 menunjukkan bahwa produktivitas per trip untuk kapal jaring purse seine dengan jumlah trip setahun 4 kali adalah 66,804 ton/trip; produktivitas per trip dengan jumlah trip setahun 5 kali adalah 50,929 ton/ trip; dan produktivitas per trip dengan jumlah trip setahun 6 kali adalah 45,619 ton/trip. Berdasarkan data tersebut dapat dinyatakan bahwa produktivitas lebih besar dihasilkan oleh kapal purse seine dengan jumlah trip yang lebih sedikit. Faktor penyebabnya adalah untuk jumlah trip 4 kali dalam setahun, lama tripnya berkisar antara 90-120 hari sehingga upaya penangkapan yang dilakukan dapat lebih optimal. Sementara itu, usaha perikanan jaring purse seine dengan jumlah trip 6 memiliki lama trip berkisar 30-60 hari, sedangkan usaha perikanan jaring purse seine dengan jumlah trip 5 lama tripnya berada diantara 61-89 hari. Pada lama trip 30-60 hari, upaya penangkapan tidak optimal dan tidak efisien karena waktu banyak terbuang untuk perjalanan berangkat dan pulang serta untuk istirahat.

Selain itu, jumlah trip yang terlalu banyak membutuhkan waktu adaptasi kembali dengan lingkungan area penangkapan yang berakibat semakin tidak efisiennya upaya penangkapan yang dilakukan. Jumlah trip yang dilakukan harus disesuaikan dengan jumlah stok ikan di lokasi penangkapan sehingga upaya penangkapan yang dilakukan lebih efisien dan mendapatkan hasil yang optimal. Alhuda dkk. (2016) menyebutkan salah satu hal yang memengaruhi produktivitas adalah jumlah upaya penangkapan (trip) yang melebihi jumlah stok sumber daya (overfishing). Hal ini juga menunjukkan bahwa besar kecilnya produktivitas per trip yang dihasilkan tidak berbanding lurus dengan banyak sedikitnya jumlah trip yang dilakukan.

\section{b) Produktivitas Per PK}

Produktivitas per PK usaha perikanan jaring purse seine dibagi menjadi 5 yaitu untuk PK mesin kapal 200, 250, 300, 350, dan 400. Hasil perhitungan produktivitas per PK disajikan pada Tabel 9.

Produktivitas per PK usaha perikanan jaring purse seine cenderung turun berbalik dengan kapasitas mesin yang semakin besar. Kondisi tersebut disebabkan karena kapasitas mesin yang semakin besar membutuhkan bahan bakar yang relatif lebih besar, sehingga persediaan bahan bakar cenderung lebih cepat terkuras serta dapat mengurangi lama trip, 
Tabel 9.

Produktivitas Parsial Per PK Usaha Perikanan Jaring Purse Seine

\begin{tabular}{cc}
\hline PK Mesin & Produktivitas Per PK (ton/PK) \\
\hline 200 & 1,179 \\
250 & 0,984 \\
300 & 0,823 \\
350 & 1,266 \\
400 & 0,550 \\
\hline
\end{tabular}

Sumber: Analisis Data Primer (2019)

yang selanjutnya akan menurunkan jumlah produksi. Kasus pada produktivitas per PK untuk PK mesin 350 PK justru mengalami peningkatan. Hal tersebut dapat disebabkan cadangan bahan bakar yang dibawa untuk kegiatan pelayaran (trip) cenderung lebih besar dibandingkan dengan jumlah bahan bakar yang dibawa oleh kapal jaring purse seine dengan kapasitas mesin (PK mesin) lain. Namun demikian, secara keseluruhan dapat diketahui bahwa besar kecilnya produktivitas per PK yang dihasilkan tidak berbanding lurus dengan besar kecilnya PK mesin kapal. Penyesuaian penggunaan kapasitas mesin dilakukan sesuai dengan kebutuhan dan rencana penangkapan yang akan dilakukan. Selain itu, penggunaan kapasitas mesin yang sesuai kebutuhan dan spesifikasi kapal dapat menjadikan suatu kegiatan penangkapan lebih efisien dari segi biaya operasional.

Rumpa dkk. (2017) menyebutkan bahwa kekuatan mesin (PK) memberikan pengaruh langsung terhadap produksi purse seine. Kekuatan mesin (PK) yang sedang atau kecepatan kapal tidak terlalu tinggi berguna untuk menyesuaikan kedalaman turunnya jaring, dimana terdapat gerombolan ikan berkumpul sehingga hasil tangkapan menjadi optimal. Penangkapan ikan lebih dipengaruhi oleh alat bantu lampu dan rumpon sehingga tidak membutuhkan kekuatan mesin (PK) atau kecepatan melingkar/setting kapal yang cepat untuk mengejarnya. Pendapat senada juga disampaikan oleh Kefi dkk. (2013) bahwa pengoperasian pukat cincin dengan alat bantu rumpon, kelajuan melingkar jaring (bergantung pada kekuatan mesin) memiliki pengaruh yang kecil pada penangkapan ikan karena sudah berkumpul di bawah rumpon. Kelajuan melingkar jaring yang secara umum cenderung menurun maka hasil tangkapan cenderung semakin meningkat.

\section{c) Produktivitas Per ABK}

Produktivitas per ABK usaha perikanan jaring purse seine dibagi menjadi 10 yaitu jumlah ABK 25, 26, 30, 34, 35, 40, 43, 45, 47, dan 50 orang. Hasil perhitungan produktivitas per ABK disajikan pada Tabel 10.

Tabel 10 menunjukkan bahwa produktivitas per ABK tertinggi terjadi pada jumlah ABK 43 orang, sementara produktivitas per ABK terendah terjadi pada jumlah ABK 50 orang. Produktivitas per ABK dari kapal purse seine cenderung fluktuatif. Fithri \& Sari (2015) menyebutkan bahwa jika output dan input naik dimana jumlah kenaikan output lebih besar dari kenaikan input, maka produktivitas akan naik. Pada kenyataannya, untuk produktivitas per ABK kapal purse seine saat jumlah $\mathrm{ABK}$ bertambah produktivitas belum tentu lebih besar dibandingkan dengan kapal purse seine yang jumlah ABKnya lebih sedikit. Hal ini karena produktivitas per ABK dipengaruhi oleh jumlah 
Tabel 10.

Produktivitas Parsial Per PK Usaha Perikanan Jaring Purse Seine

\begin{tabular}{cc}
\hline Jumlah ABK & Produktivitas Per ABK (ton/org) \\
\hline 25 & 10,600 \\
26 & 11,462 \\
30 & 8,097 \\
34 & 6,176 \\
35 & 7,069 \\
40 & 7,731 \\
43 & 16,279 \\
45 & 5,111 \\
47 & 6,277 \\
50 & 2,160 \\
\hline
\end{tabular}

Sumber: Analisis Data Primer (2019)

trip yang dilakukan dan tergantung musim penangkapan (musim paceklik).

Selanjutnya, Suryana dkk. (2013) menyebutkan bahwa jumlah ABK tidak berpengaruh signifikan terhadap hasil tangkapan. Dengan demikian, penambahan jumlah ABK belum tentu akan dapat meningkatkan produksi/hasil tangkapan. Secara umum, dari hasil yang diperoleh menunjukkan bahwa banyak sedikitnya produktivitas per ABK yang dihasilkan tidak berbanding lurus dengan banyak sedikitnya ABK yang diberangkatkan.

\section{d) Produktivitas Per GT}

Produktivitas per GT usaha perikanan jaring purse seine dibagi menjadi 19 yaitu untuk GT 70, 71, 72, 73, 74, 75, 76, 77, 79, 81, 82, 83, $84,85,86,87,88,89$, dan 90. Hasil perhitungan produktivitas per GT disajikan pada Tabel 11.

Tabel 11 menunjukkan bahwa produktivitas per GT usaha perikanan purse seine tergolong fluktuatif. Hal ini menunjukkan bahwa produktivitas usaha perikanan purse seine tidak hanya dipengaruhi oleh ukuran kapal (GT kapal), tetapi juga dipengaruhi oleh jumlah trip dalam setahun, jumlah persediaan bahan bakar yang dibawa selama pelayaran, dan kekuatan mesin yang digunakan. Imanda dkk. (2016) menyebutkan bahwa hasil tangkapan tidak hanya dipengaruhi oleh GT kapal, tetapi juga dipengaruhi oleh jumlah BBM, daya lampu, dan mesin kapal. Lebih lanjut, Limbong dkk. (2017) menyebutkan bahwa faktor-faktor yang berperan nyata pada unit alat tangkap pukat cincin (purse seine) yaitu ukuran kapal, daya mesin kapal, panjang jaring dan tinggi jaring. Secara umum, besar kecilnya produktivitas per GT yang dihasilkan tidak berbanding lurus dengan besar kecilnya GT kapal.

KepMen KP No. 61 Tahun 2014 menyebutkan bahwa produktivitas kapal penangkap ikan dengan jaring purse seine pelagis kecil di lokasi penangkapan selain utara Laut Jawa adalah 1,30 ton/GT, sedangkan rata-rata produktivitas per GT kapal purse seine adalah 3,457 ton/GT (KKP, 2014a). Dengan demikian, kapal purse seine telah melebihi peraturan yang ditetapkan sehingga perlu dilakukan pembatasan jumlah tangkapan karena mengarah ke overfishing di wilayah penangkapan Laut Jawa (WPP RI 712); Selat Makassar, Teluk Bone, Laut Flores dan Laut Bali (WPP RI 713); Laut Aru, Laut Arafuru dan Laut Timor Bagian Timur (WPP RI 718). 
Tabel 11.

Produktivitas Parsial Per GT Usaha Perikanan Jaring Purse Seine

\begin{tabular}{cc}
\hline GT Kapal & Produktivitas Per GT (ton/GT) \\
\hline 70 & 3,714 \\
71 & 3,986 \\
72 & 3,718 \\
73 & 3,651 \\
74 & 3,432 \\
75 & 3,187 \\
76 & 3,428 \\
77 & 3,169 \\
79 & 2,911 \\
81 & 2,695 \\
82 & 2,713 \\
83 & 2,771 \\
84 & 2,917 \\
85 & 3,147 \\
86 & 2,846 \\
87 & 3,724 \\
88 & 2,560 \\
89 & 3,343 \\
90 & 7,778 \\
\hline
\end{tabular}

Sumber: Analisis Data Primer (2019)

\section{KESIMPULAN DAN SARAN}

\section{Kesimpulan}

Hasil penelitian menunjukkan bahwa produktivitas kapal purse seine telah melebihi peraturan yang ditetapkan (1,30 ton/GT). Dari produktivitas parsial disimpulkan bahwa (1) besar kecilnya produktivitas per trip tidak berbanding lurus dengan banyak sedikitnya jumlah trip yang dilakukan; (2) besar kecilnya produktivitas per PK yang dihasilkan tidak berbanding lurus dengan besar kecilnya PK mesin kapal yang digunakan; (3) banyak sedikitnya produktivitas per ABK yang dihasilkan tidak berbanding lurus dengan banyak sedikitnya ABK yang diberangkatkan; (4) besar kecilnya produktivitas per GT yang dihasilkan tidak berbanding lurus dengan besar kecilnya GT kapal.

\section{Saran}

Perlu adanya pelatihan tentang manajemen usaha agar pelaku usaha perikanan khususnya jaring purse seine agar dapat menjalankan usahanya secara profesional dan efisien, terutama dalam penentuan spesifikasi kapal, penentuan jumlah trip dan penggunaan jumlah ABK.

\section{DAFTAR PUSTAKA}

Alhuda, A., Anna, Z., \& Rustikawati, I. (2016). Analisis Produktivitas dan Kinerja Usaha Nelayan Purse Seine di Pelabuhan Perikanan Pantai Lempasing, Bandar Lampung. Jurnal Perikanan Kelautan, VII(1), 30-40.

Azwar, S. (2003). Metodologi Penelitian. Jakarta: Pustaka Pelajar. 
Badan Pusat Statistik Provinsi Jawa Tengah (2019). Jawa Tengah dalam Angka Tahun 2018. Semarang: Badan Pusat Statistik Provinsi Jawa Tengah.

Balai Penelitian Perikanan Laut. (2014). Potensi dan Tingkat Pemanfaatan Sumber Daya Ikan di Wilayah Pengelolaan Perikanan Republik Indonesia ( WPP RI ). Jakarta: Ref Graphika.

Cahyadi, R. (2012). Nelayan dan Pertarungan terhadap Sumber Daya Laut. Jurnal Kependudukan Indonesia, VII(2), 127145.

Chodriyah, U. \& Hariati, T. (2010). Musim Penangkapan Ikan Pelagis Kecil di Laut Jawa. Jurnal Litbang Perikanan Indonesia, 16(3), 217-223.

Choliq, Wirasasmita, R., \& Sofyan. (1994) Evaluasi Proyek (Suatu Pengantar). Bandung: Pionir Jaya.

Damayanti, H. O. (2017). Struktur Usaha Penangkapan Ikan oleh Nelayan Tradisional di Desa Pecangaan Kecamatan Batangan Kabupaten Pati. Jurnal Litbang : Media Informasi Penelitian, Pengembangan dan IPTEK, XIII(2), 80-92.

Fithri, P. \& Sari, R. Y. (2015). Analisis Pengukuran Produktivitas Perusahaan Alsintan CV. Cherry Sarana Agro. Jurnal Optimasi Sistem Industri, 14(1), 138-155.

Gordon, J., Zhao, S. \& Gretton, P. (2015). On Productivity: Concepts and Measurement. Canberra: Commonwealth of Australia.

Hermawan, Y. \& Rustiana, E. (2019). Peningkatan Produktivitas Melalui Kohesivitas Kelompok dan Revitalisasi Kondisi. Jurnal Ilmu Administrasi (JIA), XVI(1), 51-65.

Imanda, S. N., Setiyanto, I., \& Hapsari, T. D. (2016). Analisis Faktor-Faktor yang Memengaruhi Hasil Tangkapan Kapal Mini Purse Seine di Pelabuhan Perikanan Nusantara Pekalongan. Journal of Fisheries Resources Utilization Management and Technology, 5(1), 145-152.
Kasim, K., Triharyuni, S. \& Wujdi, A. (2014). Hubungan Ikan Pelagis dengan Konsentrasi Klorofil-A di Laut Jawa. BAWAL, 6 (1), 21-29.

Kasim, K., Widodo, A. A. \& Prasetyo, A. P. (2011). Pengaruh Episode La Nina dan El Nino Terhadap Produksi Beberapa Pelagis Kecil yang Didaratkan di Pantai Utara Jawa', Jurnal Litbang Perikanan Indonesia, 17(4), pp. 257-264.

Kefi, O. S., Katiandagho, E. M., \& Paransa, I. J. (2013). Sukses Pengoperasian Pukat Cincin Sinar Lestari 04 dengan Alat Bantu Rumpon yang Beroperasi di Perairan Lolak Provinsi Sulawesi Utara. Jurnal Ilmu dan Teknologi Perikanan Tangkap, 1(3), 69-75.

Keputusan Menteri Kelautan dan Perikanan Republik Indonesia Nomor 38 Tahun 2003 tentang Produktivitas Kapal Penangkap Ikan.

Keputusan Menteri Kelautan dan Perikanan Nomor 61 Tahun 2014 tentang Produktivitas Kapal Penangkap Ikan.

Keputusan Menteri Kelautan dan Perikanan Republik Indonesia Nomor 86/KEPMENKP/2016 Tentang Produktivitas Kapal Penangkap Ikan.

Kementerian Kelautan dan Perikanan Republik Indonesia. (2017). Buku Saku Pengolah Data Alat Tangkap. Jakarta: Kementrian Kelautan dan Perikanan Republik Indonesia.

Kurniawati, F., Sanjoto, T. B. \& Juhadi. (2015). Pendugaan Zona Potensi Penangkapan Ikan Pelagis Kecil di Perairan Laut Jawa pada Musim Barat dan Musim Timur dengan Menggunakan Citra Aqua Modis. Geo Image, 4(2), 9-19.

Lesmana, I., Pamikiran, R. D. C. \& Labaro, I. L. (2017). Produksi dan Produktivitas Hasil Tangkapan Kapal Tuna Hand Line yang Berpangkalan di Kelurahan Mawali, Kecamatan Lembeh Utara, Kota Bitung. Jurnal Ilmu dan Teknologi Perikanan Tangkap, 2 (6), 205-211. 
Limbong, I., Wiyono, E. S., \& Yusfiandayani, R. (2017). Faktor-Faktor yang Memengaruhi Hasil Produksi Unit Penangkapan Pukat Cincin di PPN Sibolga, Sumatera Utara. ALBACORE, I(1), 89-97.

Ma'mun, A., Priatna, A., Amri, K. \& Nurdin, E. (2019). Hubungan Antara Kondisi Oseanografi dan Distribusi Spasial Ikan Pelagis di Wilayah Pengelolaan Perikanan Negara Republik Indonesia (WPP NRI) 712 Laut Jawa. Jurnal Penelitian Perikanan Indonesia, 25(1), 1-14.

Mahiswara, Widodo, A. A. \& Priatna, A. (2009). Sebaran Kepadatan Akustik Ikan Pelagis di Bawah Pengaruh Cahaya Lampu pada Perikanan Pukat Cincin di Laut Jawa. Jurnal Litbang Perikanan Indonesia, 15(2), 151-159.

McGowan, M. A., Andrews, D., Criscuolo, C. \& Nicoletti, G. (2015). The Future Productivity. Jerussalem: OECD.

Mirnawati, Nelwan, A. \& Zainuddin, M. (2019). Studi tentang Komposisi Jenis Hasil Tangkapan Purse Seine Berdasarkan Lokasi Penangkapan di Perairan Tanah Beru Kecamatan Bonto Bahari Kabupaten Bulukamba. Jurnal IPTEKS PSP, 6(11), 2143.

Najamuddin, Hajar, M. A. I. \& Sarira, M. (2017). Analisis Unit Penangkapan Ikan Pelagis di Kabupaten Pinrang. Jurnal IPTEKS PSP, 4(7), 79-94.

Nelwan, A. F. P., Sudirman, M. N. \& Yunus, M. A. (2015). Produktivitas Penangkapan Ikan Pelagis di Perairan Kabupaten Sinjai pada Musim Peralihan Barat-Timur. Jurnal Perikanan, XVII(1), 18-26.

Olii, M. Y. U. P. \& Iwan. (2018). Produktivitas Pukat Cincin (Purse seine) Untuk Penangkapan Ikan Cakalang (Katsuwonus pelamis) Di Perairan Kabupaten Boalemo. Gorontalo, 1(1), 33-42.

Peraturan Menteri Kelautan dan Perikanan Republik Indonesia Nomor 60 Tahun 2014 tentang Produktivitas Kapal Penangkap Ikan.
Pusat Pendidikan Kelautan dan Perikanan Ambon. (2012). Purse Seine. Ambon: Pusat Pendidikan Kelautan dan Perikanan Ambon.

Rajagukguk, K. (2018). Produktivitas Perikanan Tangkap Pukat Cincin (Purse Seine) di Pelabuhan Perikanan Nusantara Pekalongan Kota Pekalongan Provinsi Jawa Tengah (Skripsi). Pekanbaru: Universitas Riau.

Roza, E. (2017). Maritim Indonesia, Kemewahan Yang Luar Biasa. Kementrian Kelautan dan Perikanan Republik Indonesia. https://kkp.go.id/artikel/2233-maritimindonesia-kemewahan-yang-luar-biasa, diakses 9 Oktober 2018.

Rumpa, A., Najamuddin, \& Farhum, S. A. (2017). Pengaruh Desain Alat Tangkap dan Kapasitas Kapal Purse Seine terhadap Produktivitas Tangkapan Ikan di Kabupaten Bone. Jurnal IPTEKS PSP, 4(8), 144-154.

Safruddin, Zainuddin, M., \& Rani, C. (2014). Prediksi Daerah Potensial Penangkapan Ikan Pelagis Besar di Perairan Kabupaten Mamuju. Jurnal IP, 1(2), 185-195.

Saputra, S. W., Solichin, A., Wijayanto, D., \& Kurohman, F. (2011). Produktivitas dan Kelayakan Usaha Tuna Longliner di Kabupaten Cilacap Jawa Tengah. Jurnal Saintek Perikanan, 6(2), 84-91.

Satrio, H. B. (2014). Determinan Produktivitas Tenaga Kerja Industri Mebel pada Bagian Produksi di Kecamatan Kaliwates Kabupaten Jember Tahun 2014 (Skripsi). Jember: Universitas Jember.

Silitonga, C., Isnaniah, \& Syofyan, I. (2016). Studi Konstruksi Alat Tangkap Pukat Cincin (Purse Seine) di Pelabuhan Perikanan Nusantara (PPN) Sibolga Kelurahan Pondok Batu Kota Sibolga Provinsi Sumatera Utara. Fakultas Perikanan dan Ilmu Kelautan Universitas Riau (Skripsi). Pekanbaru: Universitas Riau. 
Suryana, S. A., Rahardjo, I. P., \& Sukandar. (2013). Pengaruh Panjang Jaring, Ukuran Kapal, PK Mesin dan Jumlah ABK terhadap Produksi Ikan pada Alat Tangkap Purse Seine di Perairan Prigi Kabupaten Trenggalek-Jawa Timur. PSPK Student Journal, I(1), 36-43.

Wiyono, E. S. (2012). Analisis Efisiensi Teknis Penangkapan Ikan Menggunakan Alat Tangkap Purse Seine di Muncar, Jawa Timur. Jurnal Teknologi Industri Pertanian, 22(3), 164-172.

Yadav, P. and Marwah, C. S. (2015). The Concept of Productivity. International Journal of Engineering and Technical Research (IJETR), 3(5), 192-196.

\section{BIODATA PENULIS}

Herna Octivia Damayanti, lahir 6 Oktober 1985 di Kudus Jawa Tengah. Pendidikan Magister Manajemen Sumber daya Pantai Universitas Diponegoro tahun 2016. Saat ini bekerja sebagai Peneliti di Badan Perencanaan Pembangunan Daerah Kabupaten Pati. 
